Technological University Dublin

DÜBLIN

ARROW@TU Dublin

2009-01-01

\title{
Electro-optical Switching of the Holographic Polymer-dispersed Liquid Crystal Diffraction Gratings
}

\author{
Pavani Kotakonda \\ Technological University Dublin \\ Izabela Naydenova \\ Technological University of Dublin, izabela.naydenova@tudublin.ie \\ Raghavendra Jallapuram \\ Technological University of Dublin
}

See next page for additional authors

Follow this and additional works at: https://arrow.tudublin.ie/cieoart

\section{Recommended Citation}

Pavani, K. et al. (2009). Electro-optical switching of the holographic polymer-dispersed liquid crystal diffraction gratings. Journal of Optics A: Pure and Applied Optics, vol. 11, no. 2. doi:10.1088/1464-4258/ $11 / 2 / 024023$

This Article is brought to you for free and open access by the Centre for Industrial and Engineering Optics at ARROW@TU Dublin. It has been accepted for inclusion in Articles by an authorized administrator of ARROW@TU Dublin. For more information, please contact arrow.admin@tudublin.ie, aisling.coyne@tudublin.ie, gerard.connolly@tudublin.ie.

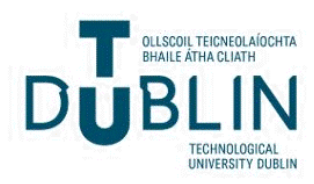




\section{Authors}

Pavani Kotakonda, Izabela Naydenova, Raghavendra Jallapuram, Suzanne Martin, and Vincent Toal 


\title{
Electro-optical switching of the holographic polymer-dispersed liquid crystal diffraction gratings
}

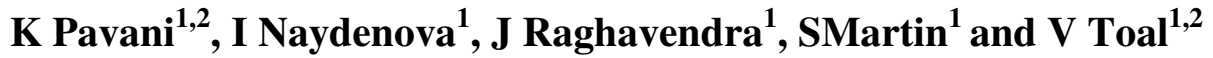 \\ 1 Centre for Industrial and Engineering Optics, Dublin Institute of Technology, Kevin Street, Dublin 8, Republic of \\ Ireland \\ ${ }_{2}$ School of Physics, Dublin Institute of Technology, Kevin Street, Dublin 8, Republic of Ireland
}

Received 15 July 2008, accepted for publication 20 November 2008

Published 15 January 2009

Online at stacks.iop.org/JOptA/11/024023

\begin{abstract}
Polymer-dispersed liquid crystal (PDLC) is a material promising for application in optical communications, diffractive optics and optical data storage. Diffraction gratings were optically recorded in a novel PDLC material developed at the Centre for Industrial and Engineering Optics. Details of the fabrication and preliminary results of electro-optical switching of the holographic PDLC (HPDLC) diffraction gratings are presented. The redistribution of LCs was observed by using phase contrast microscopy and confocal Raman spectroscopy.
\end{abstract}

Keywords: diffraction grating, holographic recording materials, liquid crystals, polymer-dispersed liquid crystals

\section{Introduction}

Switchable holographic optical devices are promising for a wide range of applications such as imaging [1], information processing [2] and diffractive optics [3]. Generally these switchable optical devices use materials that exhibit a change in the refractive index with an applied external field. Previously, switchable diffraction gratings and polarization rotators were successfully fabricated by filling optically recorded surface relief gratings in an acrylamide-based photopolymer with LCs [4, 5]. Liquid crystals (LCs) are useful for the fabrication of these devices because of their ability to change their orientation in an applied external field and to exhibit a large change in refractive index [6, 7]. Selfprocessing photopolymers are holographic recording media characterized by significant advantages such as high speed of recording with no need of processing after recording and capability of recording at different wavelengths by selecting suitable sensitizing dyes [8-11]. The combination of LCs and photopolymers offers a unique approach to the economical fabrication of electrically switchable devices. These composite materials are known as polymer-dispersed liquid crystals (PDLC) in which liquid crystal droplets are embedded in a polymer matrix $[12,13]$. A comprehensive review of HPDLC is given by Bunning et al [14]. Though there are a number of impressive reports describing the performance parameters of these switchable holographic materials [14-24] there is still a growing need to produce materials that offer high diffraction efficiencies (DE), low switching fields and fast response times. Recently, new kinds of holographic gratings (POLICRYPS and POLIPHEM) were proposed that avoid LC droplet formation and realize a channel structure in which the polymer and LC molecules are almost completely phase separated $[25,26]$. As a consequence very high diffraction efficiencies and time response in the microseconds can be achieved [26]. 
This paper presents a novel PDLC material used to record transmission HPDLC diffraction gratings. Different classes of monomers [14] have been used in HPDLC formulation such as acrylate monomers [15, 17], urethane resins [27] and Norland resins [28-30]. In some of the formulations, $N$-vinyl pyrrolidinone $(N V P)$ has been used as a reactive diluent. The role of $N V P$ in curing of the polymer is not well understood [14]. In this work acrylamide, $N, N_{-}$-methylenebisacrylamide and n-vinyl2-pyrrolidinone $(N V P)$ are used. The use of acrylamide and $N, N_{-}-$ methylenebisacrylamide as monomers in HPDLC formulations is reported for the first time in this paper. NVP helps to dissolve the different components in the mixture and to form a homogeneous solution. It was previously observed that increasing the amount of NVP in the solution helps to decrease the droplet size [31]. In the work presented here erythrosine $\mathrm{B}$, a xanthene dye, is used as a photoinitiator and triethanolamine (TEA) is used as a co-initiator. The electrooptical performance and diffraction efficiency of the HPDLCs depend on the choice of the liquid crystal. The refractive index of the polymer $(n p)$ matches the ordinary refractive index of the LCs $(n o)$. In this work E7 with optical anisotropy $(n) 0.225$ and ordinary refractive index (no) 1.521 is used.

Preliminary results on the fabrication and characterization of transmission HPDLC gratings are reported. The electrooptical switching behaviour was studied by measuring the light intensity in the zero order and in the first order of diffraction. The performance of HPDLC depends on the different parameters in which morphology of the LC/polymer composite, LC droplet size and redistribution of LC droplets play important roles $[14,32]$. The redistribution of LC droplets was observed by using phase contrast microscopy and confocal Raman spectroscopy.

\section{Theory}

The basic methods used for preparing PDLC materials are phase separation and encapsulation. Here HPDLC diffraction gratings were fabricated using the phase separation technique.

In this technique one starts with a homogeneous solution of polymer and LCs. The separation of LC droplets takes place due to polymer solidification. There are three causes of phase separation: solvent-induced phase separation (SIPS), thermally induced phase separation (TIPS) and polymerization-induced phase separation (PIPS) [13]. When a PDLC layer consisting of monomers, photoinitiator and LCs is exposed to an optical interference pattern, PIPS results in spatially periodic structures with alternating polymer-and LC-rich planes in the volume of the layer. A diffraction grating is created as a result of refractive index modulation between polymer-and LCrich planes as shown in figure 1.

Linearly polarized light is used to study the electro-optical switching behaviour of the gratings. The simplified model of the operation of an HPDLC diffraction grating is shown in figure 2 . When no field is applied to the grating, the directors of the LC droplets within the layer are randomly oriented.

As a result, incident linearly polarized light probes a range of refractive index values between no and ne, which are the ordinary and extraordinary refractive indices of LCs and are different from the refractive index of photopolymer $\left(n_{\mathrm{p}}\right)$ and hence the diffraction grating is in the ON state. When a sufficiently large electric field is applied, the LC molecules in the droplets are collectively reoriented with their directors parallel to the applied field. Under this condition $n_{\mathrm{p}}=n \mathrm{o}$ resulting in the disappearance of diffraction orders and this state is known as the OFF state [14]. 


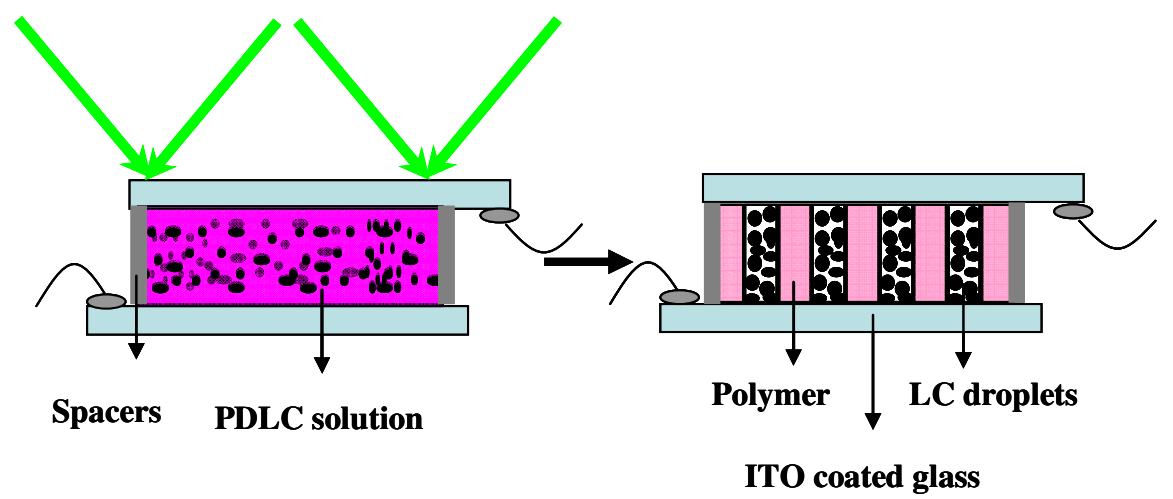

Figure 1 Creation of diffraction grating in PDLC layer.

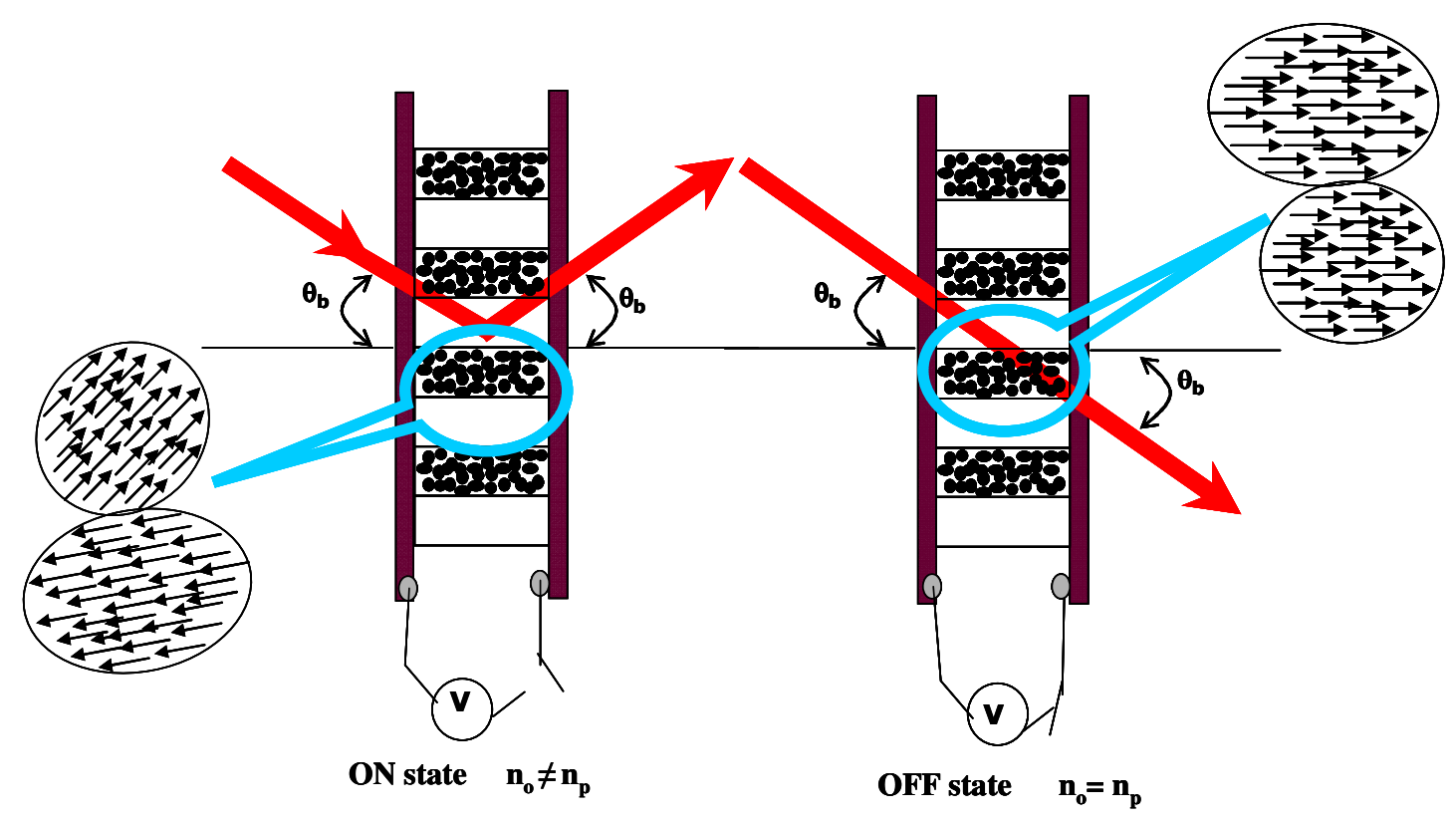

Figure 2 Operation of switchable HPDLC diffraction grating.

\section{Experimental details}

\subsection{Sample preparation}

The components of this material are E7 LCs, $N V P$, acrylamide and $N, N_{-}-$ methylenebisacrylamide monomers, TEA initiator and erythrosin B sensitizing dye. The E7 LCs and $N V P$ were mixed well by using a magnetic stirrer and the remaining components were added and mixed well with the stirrer and the solution placed in an ultrasonic bath for 15-30 min and the dye was added finally. The ultrasonic mixing creates uniform PDLCs. The mixture consists of $89: 11 \%$ by weight of prepolymer and LCs. Cells made from ITO coated glass plates were filled with this solution as shown in figure 1.

Teflon spacers were placed on one ITO coated glass plate and another ITO coated glass plate was placed on the spacers. The thickness of the empty cell is around $10 \mu \mathrm{m}$ and is measured with a white light interferometer. Two sides of the assembly were glued, keeping the other two sides open for filling the cell cavity with PDLC material by capillary action. After filling, the open sides of the cell were glued immediately to avoid air gaps. Electrical contacts were made by using silver loaded epoxy resin. 


\subsection{Experimental set-up}

A spatially filtered and collimated laser of wavelength $532 \mathrm{~nm}$ was used to record transmission HPDLC diffraction gratings. The laser beam was split by a beamsplitter into two beams which were made to interfere at the PDLC layer as shown (figure 3). The spatial frequency of the gratings was calculated by using the Bragg equation $2 \_\sin \theta=\lambda$, where _ is the fringe spacing, $\theta$ is half the angle between the interfering beams and $\lambda$ is the wavelength. The spatial frequency of PDLC diffraction grating the interference pattern was adjusted to 200 lines mm-1 (for Raman spectroscopy studies to be discussed later), 300 and 1000 lines mm-1 by adjusting the angle between the two beams.

The optical set-up used to study electro-optical switching behaviour of the diffraction grating is shown in figure 4 . A linearly polarized laser beam, wavelength $633 \mathrm{~nm}$, was used to probe the device. The intensities in the zero and first orders were measured while applying a square wave voltage at $1 \mathrm{kHz}$. The diffraction efficiency $(\eta)$ and transmissivity ( $T$ ), expressed as percentages are given by equations (1) and (2) respectively:

$$
\begin{aligned}
& \eta=I_{1} /\left(I_{0}+I_{1}\right) \times 100(1) \\
& T=\left(I_{0}+I_{1}\right) / I_{\mathrm{i}} \times 100(2)
\end{aligned}
$$

where $I_{0}$ is the intensity of the zero order, $I_{1}$ is intensity of the first order and $I_{\mathrm{i}}$ is the intensity of the incident beam.

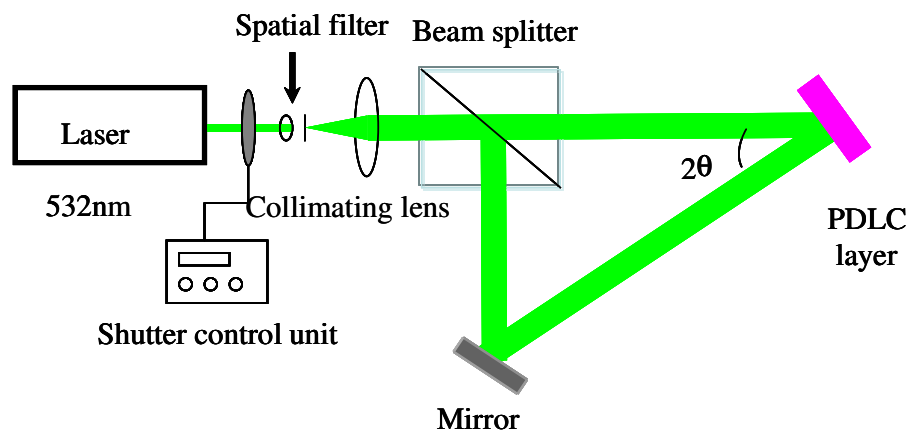

Figure 3 Experimental setup used to record diffraction gratings.

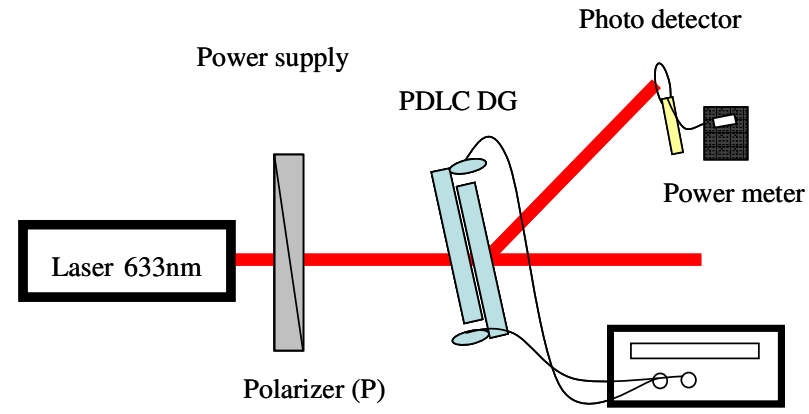

Figure 4 Experimental setup to study electro optical properties of PDLC diffraction grating. 


\section{Results}

Switchable diffraction gratings were recorded in PDLC layers of $10 \mu \mathrm{m}$ thickness by exposing them to interference patterns of light at 300 and 1000 lines mm-1 under various exposure conditions, of which $10 \mathrm{~mW}$ cm-2 recording intensity for $35 \mathrm{~s}$ proved optimal for obtaining the highest diffraction efficiencies. After recording the diffraction gratings were uniformly exposed to UV light of intensity $16 \mathrm{~W}$ for $20 \mathrm{~s}$ to completely polymerize the remaining material.

The value of $\eta$ was calculated by using equation (1) and is shown in figure 5. Initial results for $\eta$ obtained at 300 and 1000 lines mm-1 were $50 \%$ and $20 \%$, respectively. Although there are HPDLC gratings which show better performance than the gratings reported in this paper [14], the results presented here are initial observations of HPDLC gratings in a new PDLC composition. The switching behaviour of the diffraction gratings was characterized by measuring the intensities in the zero and first orders of diffraction with applied AC voltage. It was observed that the first-order diffracted beam disappears at around $2.5 \mathrm{~V} \mu \mathrm{m}-1$ in the 300 lines $\mathrm{mm}-1$ grating and

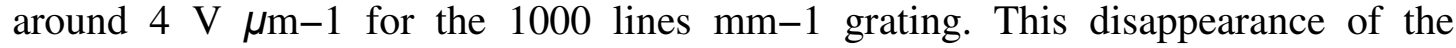
diffracted light is due to the refractive index of the LC droplets (directors aligned parallel to the applied field) matching the refractive index of the polymer. In the HPDLC diffraction grating of 1000 lines $\mathrm{mm}-1$ in a $5 \mu \mathrm{m}$ thick layer reported by Harbour et al, complete switching was observed at a much higher field of $40 \mathrm{~V} \mu \mathrm{m}-1$ [33].

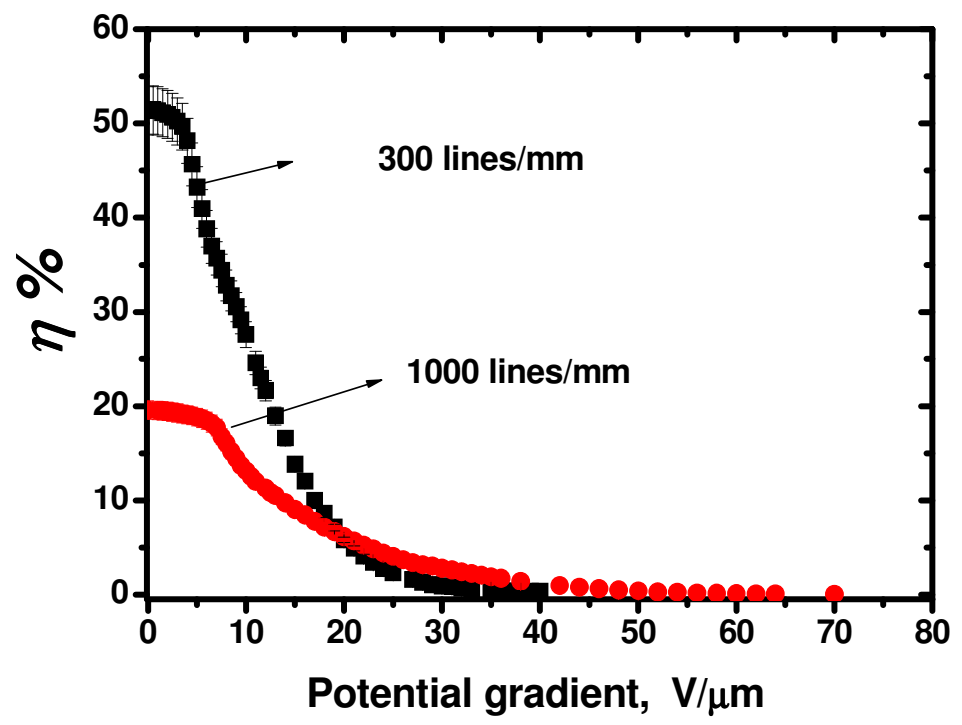

Figure $5 \mathrm{DE} \%$ Vs potential gradient $(\mathrm{V} / \mu \mathrm{m})$ at 300 lines $/ \mathrm{mm}$ and at 1000 lines $/ \mathrm{mm}$. 


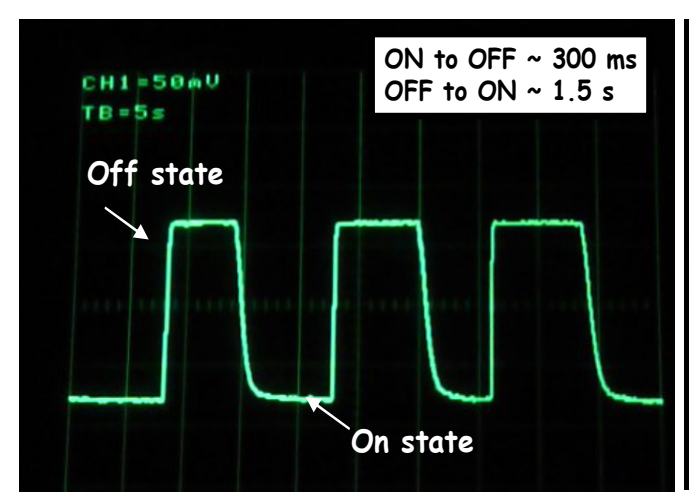

(a)

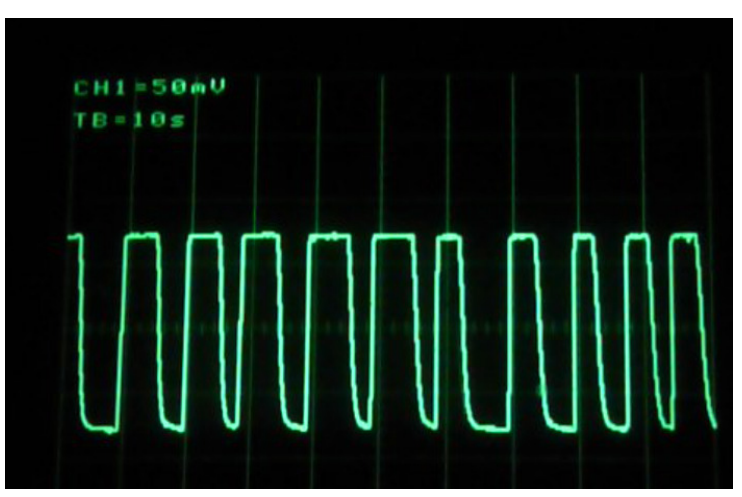

(b)

Figure 6 The response of the switchable diffraction grating at 1000 lines/mm

The time response of the switchable diffraction grating at 1000 lines $\mathrm{mm}-1$ is shown in figure 6(a). Repeatability of the switching behaviour is shown in figure 6(b). From figure 6(a) it is seen that the diffraction grating switches OFF in $300 \mathrm{~ms}$ and when the voltage is removed the grating switches $\mathrm{ON}$ in $1.5 \mathrm{~s}$. This switching behaviour is slow compared to other reported devices $[14,33]$ but these are initial results and they show promise for further optimizing the composition of the material, recording conditions, thickness of the device, size of the LC droplets and switching voltage. The switching of the diffraction orders at 300 lines $\mathrm{mm}-1$ is shown in figure 7 . The redistribution of LC droplets in the grating with spatial frequency of 300 lines mm-1 was studied using phase contrast microscopy. Figure 8 shows that the LC droplet size is approximately equal to the fringe spacing, i.e. around $3 \mu \mathrm{m}$. As the droplet size matches the fringe spacing, in the 1000 lines mm-1 grating the LC droplet size would be around $1 \mu \mathrm{m}$. The faster response of the 300 lines $\mathrm{mm}-1$ grating also supports the suggestion that the LC droplet size is greater in the gratings with 300 lines mm-1.

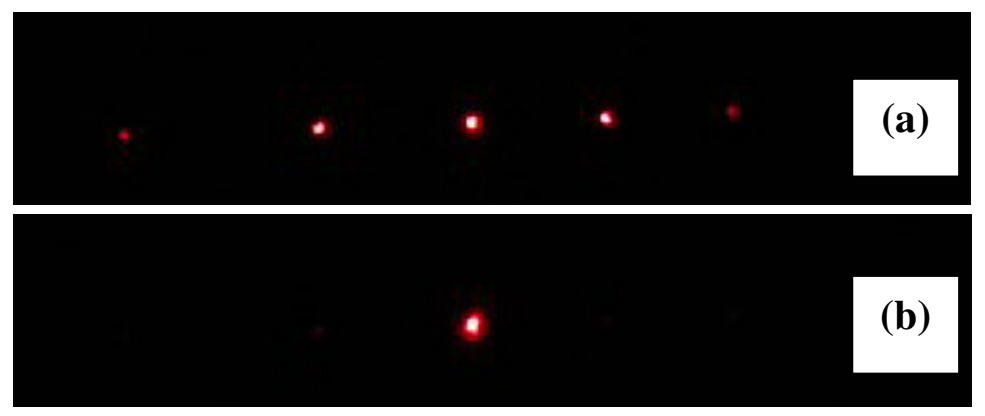

Figure 7 Diffraction patterns for 300 lines $/ \mathrm{mm}$ at $V=0 \mathrm{~V} / \mu \mathrm{m}$ (a) and at $V=4 \mathrm{~V} / \mu \mathrm{m}$ (b). 


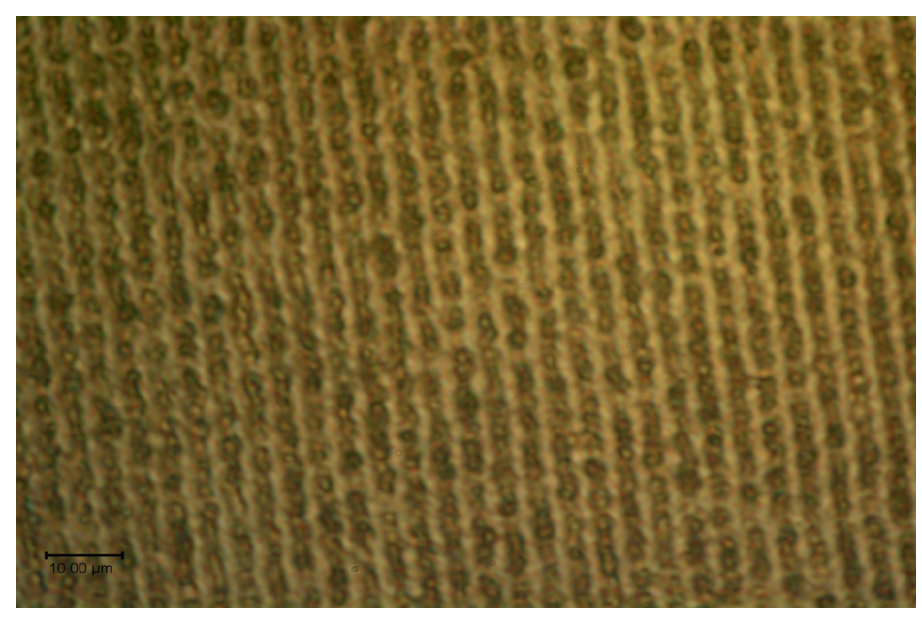

Figure 8 Phase contrast microscope image of redistribution of LC droplets at 300 lines $/ \mathbf{m m}$.

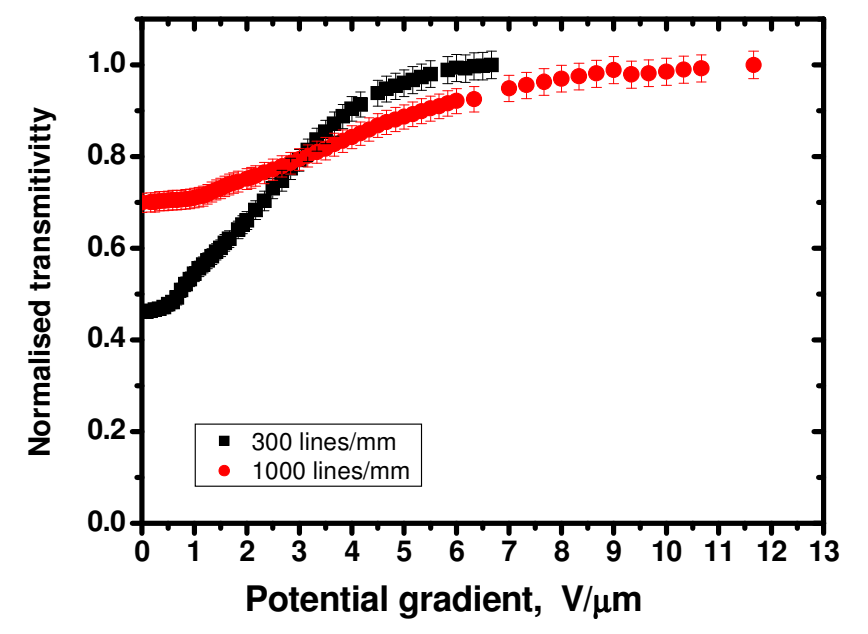

Figure 9 Normalised transmittivity Vs potential gradient $(\mathrm{V} / \mu \mathrm{m})$ at $300 \mathrm{lines} / \mathrm{mm}$ and at 1000 lines/mm.

Figure 9 shows the normalized transmissivity versus applied electric field at 300 and at 1000 lines mm-1. At both spatial frequencies transmissivity increases with the field which shows that the scattering losses are high at the beginning and reduce with applied electric field. The slope of the transmissivity curve at 300 lines $\mathrm{mm}-1$ is greater than that at 1000 lines mm-1. This suggests that scattering is greater at 300 lines $\mathrm{mm}-1$ than at $1000 \mathrm{~mm}-1$ lines, as expected for larger droplet size at 300 lines mm-1. The difference in the LC droplet size is most probably the reason for the higher switching voltage at 1000 lines mm-1 compared with 300 lines mm-1. The switching voltage is expected to be higher when the droplet size is smaller [13]. These results were confirmed by Raman spectroscopy which has several advantages over other spectroscopic techniques such as noninvasiveness and no need for sample preparation. Blach et al studied LC ordering and director field distribution inside individual droplets in PDLC material using confocal micro-Raman spectroscopy [34]. To study the orientation of LC droplets in a PDLC diffraction grating the carbon- 
nitrogen triple bond $(\mathrm{C} \equiv \mathrm{N})$ stretching vibrational band at $2226 \mathrm{~cm}-1$ was used [34] and is shown in figure 10 .

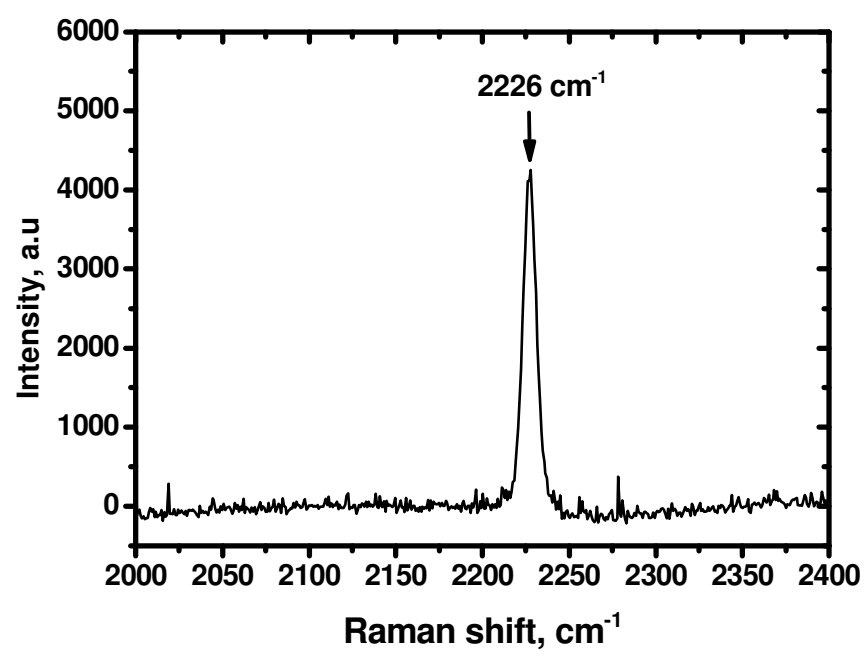

Figure 10 Raman Band of the $\mathrm{C} \equiv \mathrm{N}$ at $2226 \mathrm{~cm}^{-1}$.

Samples were recorded at 200 lines $\mathrm{mm}-1$, with a recording intensity of $5 \mathrm{~mW} \mathrm{~cm}-2$ for $140 \mathrm{~s}$. After recording the sample was uniformly polymerized with UV light intensity for $15 \mathrm{~min}$. Probing of the sample was carried out at $514 \mathrm{~nm}$ wavelength. The spectra were recorded in the range of 2000-2400 cm-1 with a spatial resolution of $1.3 \mu \mathrm{m}$. All the spectra were fitted with a Lorentz function and a linear baseline.

Figure 11 shows Raman mapping across the PDLC grating at $2226 \mathrm{~cm}-1$ and the Raman image of the grating. It is observed that the intensity of the band changes periodically with a spatial period of $5 \mu \mathrm{m}$ which confirms that the LC
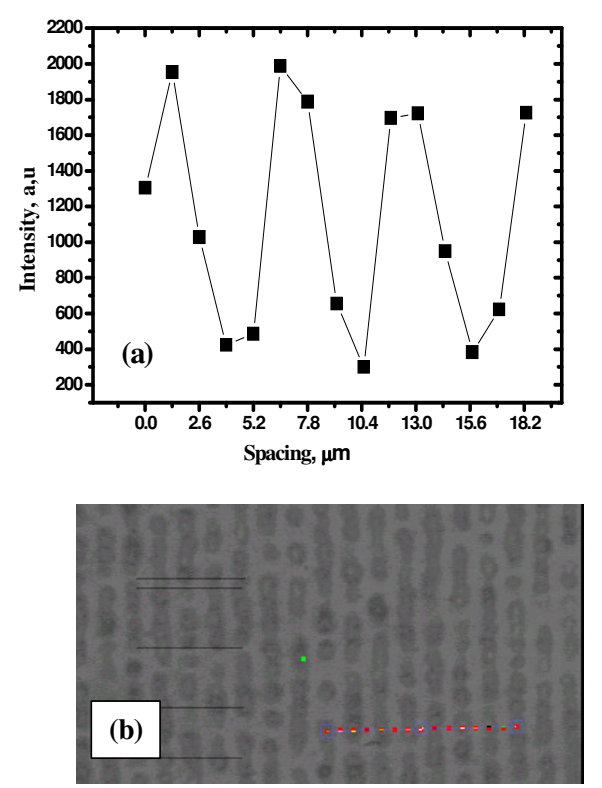

Figure 11. Raman mapping of the $\mathrm{C} \equiv \mathrm{N}$ band across the PDLC grating (a) and Raman image of the PDLC grating (b). droplets are aligned regularly and the size of the droplets is equal to the fringe spacing $(5 \mu \mathrm{m})$. 


\section{Conclusions}

HPDLC diffraction gratings were fabricated by using a novel PDLC composition. The electro-optical switching of the diffraction gratings was demonstrated. The redistribution of the LC droplets was studied using phase contrast microscopy and confocal Raman spectroscopy. These studies show the potential of this new material for the fabrication of electrically switchable liquid crystal devices. However, further experiments are needed to understand the role of the new components in the HPDLC material. To improve the performance of the devices, recording conditions, composition and thickness of the material are being optimized.

\section{Acknowledgments}

KP would like to acknowledge the Dublin Institute of Technology, Faculty of Science for financial support and the Focas Institute for providing the excellent laboratory facilities.

\section{References}

[1] Caputo R, Sio L D, Veltri A, Umeton C P and Sukhov A V 2006 J. Dis. Technol. $238-51$

[2] Natarajan L V, Sutherland R L, Bunning T J and Tondigila V P 1998 Proc. SPIE $329244-51$

[3] Cipparrone G, Mazzulla A and Russo G 2001 Appl. Phys. Lett. 78 1186-8

[4] Pavani K, Naydenova I, Martin S, Jallapuram R, Howard R G and Toal V 2007 Opt. Commun. 273 367-9

[5] Pavani K, Naydenova I, Howard R G, Martin S and Toal V 2007 JMSE http://www.springerlink.com/content/ 94q74310028101t9/ published online [6] Bahadur B 1990 Liquid Crystals: Applications and Uses vol 1 (Singapore: World Scientific)

[7] McEwen R S 1987 J. Phys. E: Sci. Instrum. 20 367-77

[8] Booth B L 1975 Appl. Opt. 14 593-601

[9] Trout T, Schmieg J, Gambogi W andWeber A 1998 Adv. Mater. 10 1219-24

[10] Martin S, Feely C A and Toal V 1997 Appl. Opt.36 5757-68

[11] Jallapuram R, Naydenova I, Martin S, Howard R, Toal V, Frohmann S, Orlic S and Eichler H J 2006 Opt. Mater.28 1329-33

[12] Mucha M 2003 Prog. Polym. Sci. 28 837-73

[13] Doane J W 1990 Liquid Crystal: Applications and Uses vol 1 (Singapore: World Scientific) chapter 14 pp 362-95

[14] Bunning T J, Natarajan L V, Tondiglia V P and Sutherland R L 2000 Annu. Rev. Mater. Sci. 30 83-115

[15] Sutherland R L, Natarajan L V, Tondiglia V P and Bunning T J 1993 Chem. Mater. 5 1533-8

[16] Lucchetta D E, Criante L and Simoni F 2003 J. Appl. Phys. 93 9669-74

[17] Zharkova G, Samsonova I, Streltsov S, Khachaturyan V,Petrov A and Rudina N 2005 Microelectron. Eng.81 281-7

[18] Beev K, Criante L, Lucchetta D E, Simoni F and Sainov S 2006 J. Opt. A: Pure Appl. Opt. 8 205-7

[19] Malcuit M S, Holmes M E and Rodriguez M A 2002 LasersElectron. Opt. 395-6

[20] Ramsey R A and Sharma S C 2005 Opt. Lett. 30 592-4

[21] Qi J and Crawford G P 2004 Displays 25 177-86

[22] Fuh A Y G, Lee C R and Mo T S 2001 Appl. Phys. Lett.78 1186-8 
[23] JazbinsekM, Olenik I D, Zgonik M, Fontecchio A K and Crawford G P $2001 \mathrm{~J}$. Appl. Phys. 90 3831-7

[24] Park M S and Kim B K 2006 Nanotechnology 17 2012-7

[25] Caputo R, Sio L D, Sukhov A V, Veltri A and Umeton C 2004 Opt. Lett. 29

$1261-3$

[26] Abbate G, Vita F, Marino A, Tkachenko V and Slussarenko S 2005 Opt. Pur. y

Apl. 38 11-9

[27] Bowley C C, Fontecchio A K, Crawford G P, Lin J J, Li L and Faris S 2000 Appl. Phys. Lett. 76 523-5

[28] Beev K, Sainov S, Angelov T and Petrov A G 2004 J. Optoelectron. Adv. Mater. 6 799-803

[29] Holmstrom S A, Natarajan L V, Tondigilia V P, Sutherland R L and Bunning T J 2004 Appl. Phys. Lett. 85 1949-51

[30] Ren H and Wu S T 2002 Appl. Phys. Lett. 81 3537-9

[31] White T J, Liechty W B, Natarajan L V, Tondiglia V P, Bunning T J and

Guymon C A 2006 Polymer 47 2289-98

[32] Malik P and Raina K K 2004 Opt. Mater. 27 613-7

[33] Harbour S, Simonyan L and Galstian T 2007 Opt. Commun.277 225-7

[34] Blach J F, Daoudi A, Buisine J M and Bormann D 2005 Vib. Spectrosc. 39 31-6 